\section{The Italian Centro 3R: Mission and early achievements pre- sented during the Second Annual Meeting}

\author{
Arti Ahluwalia \\ Department of Information Engineering \\ and Centro di Ricerca "E. Piaggio", \\ University of Pisa, Pisa, Italy
}

The Italian Interuniversity Center for the Promotion of the $3 \mathrm{Rs}$ principles in Teaching and Research, also known as Centro 3R, was established in December 2017. Since then its membership has increased to 6 universities and it continues to grow, attracting numerous members.

The Center stands out with respect to other associations, both in terms of its objectives as well as its inclusivity of all 3Rs and all researchers, whether they study animals or not. Its guiding principles are underpinned by a rational, objective and humane science-based approach to biomedical research, as underlined by the EC directive 2010/63 and the corresponding Italian legislation (DL 2014/26). As does the Directive, we do stress that "the final goal (of humane research) is full replacement of procedures on live animals for scientific and educational purposes as soon as it is scientifically possible to do so". Thanks to this inclusive approach, it is becoming a point of reference for research and teaching resources in Italian academia and a platform for discussions. Indeed, since its inception, the Centro 3R has sought to engage students, researchers, policymakers and the public to underline the importance of the 3Rs in biomedical research - not only from an ethical perspective but because a properly designed experiment which takes into account animal welfare and better technology renders quality data. Besides the institution of courses in degree programs and the sharing of best practices, the Center holds an annual meeting to encourage dialogue and cross-disciplinary exchange between the scientific community, the public and other stakeholders.

These Special Issues of Biomedical Science and Engineering are dedicated to the 2019 Annual Meeting of Centro 3R. As attested by the abstracts, the Centro 3R brings together a range of expertise in disci- plines such as pharmacology, engineering, veterinary science, law, biology, medicine and philosophy. Additionally, attention is being paid to the development of courses on the 3 Rs within the different degree programs offered by the participating universities. Two examples have been presented by Bassi $^{1}$ and Chiono ${ }^{2}$ while Dura and Holloway ${ }^{3}$ have described the resources made available by EURL-ECVAM. Of interest to biomedical engineers and scientists are the novel models of epithelial tissues: some focus on corneal epithelia for drug delivery and permeability studies, 4,5 bioreactors with integrated TEER and flow as physiologically relevant in vitro models 6 (bioreactors with cyclic) membrane deformation for lung models. ${ }^{7}$ Given the extensive expertise on materials and materials engineering in the Centro $3 \mathrm{R}$, many examples of novel scaffolds are reported too. ${ }^{8-12}$

In conclusion, these special issues are testament to the depth and breadth of work being performed in Italy as well as the commitment of its scientists to the principles of the $3 \mathrm{Rs}$.

\section{References}

1. Bassi AM. Teaching and training in substitutive approaches to animal testing: Commitment of the University of Genoa. Biomed Sci Eng 2019;3:81.

2. Chiono V. Approaching 3R teaching in biomedical engineering. Biomed Sci Eng 2019;3:84.

3. Dura A, Holloway M. Characterising the current provision of education and training courses relevant to the Replacement, Reduction and Refinement (Three Rs) of animals used for scientific purposes. Biomed Sci Eng 2019;3:88

4. Burgalassi S, Zucchetti E, Terreni E, et al. Reconstituted epithelial corneal tissues for evaluation of drug delivery. Biomed Sci Eng 2019;3:82.

5. Zucchetti E, Monti D, Chetoni P, et al. Reconstituted epithelial tissues and native cornea: A comparison of the influence of surfactants on ocular permeability. Biomed Sci Eng 2019; 3:123.

6. Cacopardo L, Costa J, Guazzelli N, et al. Real-time cellular impedance monitoring and imaging in a dual-flow biore-
Correspondence: Arti Ahluwalia, Department of Information Engineering, University of Pisa, Pisa, Italy

E-mail: arti.ahluwalia@unipi.it

Key words: Reduction; refinement, replacement; animal experimentation; teaching; basic research.

Conference presentation: this paper was presented at the Second Centro 3R Annual Meeting - 3Rs in Italian Universities, 2019 , June 20-21, University of Genoa, Italy.

Received for publication: 28 October 2019.

Accepted for publication: 6 November 2019.

This work is licensed under a Creative Commons Attribution NonCommercial 4.0 License (CC BY-NC 4.0).

CCopyright: the Author(s), 2019

Licensee PAGEPress, Italy

Biomedical Science and Engineering 2019; 3(s2):79 doi:10.4081/bse.2019.79

actor. Biomed Sci Eng 2019;3:104.

7. Nossa R, Costa J, Cacopardo L, Ahluwalia A. Engineering a dynamic model of the alveolar interface for the study of aerosol deposition. Biomed Sci Eng 2019;3:115.

8. Cascone MG, Lazzeri L, Rossellini E. Tissue engineered constructs for the replacement of laboratory animals: Biomimetics and microfluidics. Biomed Sci Eng 2019;3:83.

9. Ciardelli G. On the transferability of tissue engineering technologies to the design of tissue models. Biomed Sci Eng 2019;3:85.

10. Conci G, Jacchetti E, Zandrini T, et al. Quantification of the foreign body reaction by means of a miniaturized imaging window for intravital nonlinear microscopy. Biomed Sci Eng 2019;3:106.

11. Di Lisa D, Tedesco M, Dellacasa E, et al. Chitosan biopolymer: Alternative adhesion factor and scaffold matrix for 2D and 3D neuronal cultures. Biomed Sci Eng 2019;3:107.

12. Zoso A, Carmagnola I, Ruocco G, et al. In vitro models of human cardiac fibrotic tissue on bioartificial scaffolds. Biomed Sci Eng 2019;3:122. 